\title{
MODELING AND EXPERIMENT OF ELECTROMAGNETIC ENERGY HARVESTER SYSTEM BY USING DUAL MOVING MECHANICAL SYSTEMS AT LOW FREQUENCY RANGE.
}

\author{
M. Z. A. Rahim, M. N. H. Hamid", Z. N. M. Yusuf, S. N. M. Soid and M. R. \\ Ibrahim
}

Universiti Kuala Lumpur Malaysian Spanish Institute,

Kulim Hi-Tech Park

*Corresponding: mnajib@unikl.edu.my

\begin{abstract}
This paper presented a concept of single degree of freedom (SDOF) electromagnetic vibration energy harvester device. This technique enable system to operate at wideband frequency range, low frequency and has multi-resonance frequencies. Each mechanical system operates at difference frequency where each system is attached with electromagnetic transducer components. The device is developed based on the parameter factors of vibration transmissibility from external vibration sources into the device through mathematical modelling. A prototype was tested by using vibration exciter and normal human walking. The fabricated device had showed multi-resonant behavior at 4.26 and $8.34 \mathrm{~Hz}$ during test. From experiment results, they have showed capability to operate at wide bandwidth frequency from 1.9 until $18.5 \mathrm{~Hz}$ at a periodic excitation of $0.04 \mathrm{~g}$. The highest amount of rms voltage that has been produced about $108 \mathrm{mV}$ with a maximum $78 \mu \mathrm{W}$ average power across the $150 \Omega$ load resistance. So, it has proven the dual-moving mechanical concept with low damping value in system has increased the operating bandwidth frequency and also increased the amount of output voltage from device.
\end{abstract}

Keywords: Parameter factor, Vibration transmissibility ratio, Electromagnetic vibration energy harvester system.

\section{INTRODUCTION}

Scavenging energy from mechanical vibration become the most study for harvesting research area due to its high availability in technical environments[1]. Vibrations have garnered the most interest because of their abundance, high theatrically achievable conversion efficiency and vibration transmissibility through different media [2]. The main mechanisms in energy harvester system are mechanical system and type of transducer. Mechanical mechanism system is more on physical design which involved the motional design [3] and a transducer is device that converts mechanical motion into electrical energy [4]. The transducer type commonly used in vibration energy harvesting is electromagnetic[2][5]. The capability of system to operate at wideband frequency depends on the mechanical design of system itself. In order to increase the system efficiency, many researchers are focusing on developing system with capability to operate under wideband frequency condition and had caused the varieties in design of system has been introduced [6][7][8]. 
In this paper, we developed electromagnetic vibrational energy harvester to improve the performance of the linear harvester based on the parametric factor involved in mechanical design in order to operate the system at time-varying frequency.

\section{MOTIVATION AND SYSTEM DESIGN}

\section{Challenges in mechanical system for energy harvester.}

Bandwidth and linearity of energy harvester are common problem faced by many researchers. Narrow bandwidth implies constrained resonance frequency and limit applications. The range of frequency depends on the efficiency of the system linearity. The mechanical design of energy harvester system will influence the capability of the system to operate at bandwidth frequency range. The lack of focusing in designing of electromechanical system (EMS) caused the limitation to fully utilize vibration level from the external sources (ambient sources) where reduce capability of energy harvester system to amplify the vibration level that indirectly it will influence the performance of system. This problem related to mechanical system mechanism. The efficiency of energy harvester system is determined based on amount of output voltage and ability to operate in wide operating frequency range.

\section{Architecture, mechanism and its operation of proposed system}

Mechanical system in energy harvester system is depend on parameter factors such as block mass (m), spring constant (k), and damping coefficient (d). In this research, the mechanical system of harvester has been developed based on parameters factor and linear behavior. Figure 1 illustrated the design system which had fully assembled. It also consists of electromagnetic system: magnet (3) and copper coil (4). All components involved in design are marked with numerical symbol as depicted in Figure 1 and explanation for each of components detail has been stated in table 1.

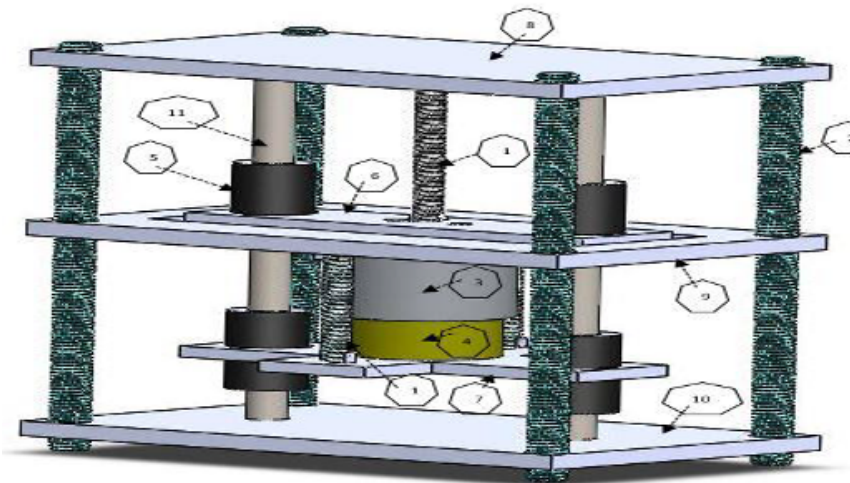

Table 1. Components description of energy harvester system

\begin{tabular}{|c|l|c|l|}
\hline No. & Components. & No. & Components. \\
\hline 1 & Compressed spring & 7 & Lower stage \\
\hline 2 & Thread road & 8 & Upper fixture \\
\hline 3 & Magnetic core & 9 & Middle fixture \\
\hline 4 & Copper coil & 10 & Base fixture \\
\hline 5 & Linear bearing & 11 & Linear shaft \\
\hline 6 & Upper stage & \multicolumn{2}{|c}{} \\
\cline { 1 - 2 } & \multicolumn{2}{|l}{} \\
\cline { 1 - 2 }
\end{tabular}

Figure 1. Proposed design for energy harvester system

In the system, mechanical system was divided into two mechanical subsystems which were upper system and lower system as depicted in Figure 2. Direction motion for mechanical subsystems has been fixed to operate in horizontal motion. Since the system used electromagnetic system as transducer, the motion between magnet and copper coil are very significant on determine the energy harvester system performance. That why, in proposed design has been built with two moving mechanical system in order to increase the performance of system. The upper system was attached with magnet core while the lower system was attached with copper coil as shown in Figure 2. 


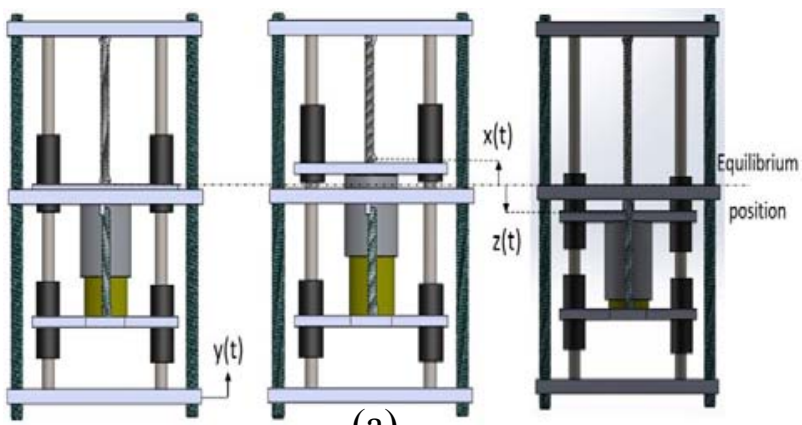

(a)

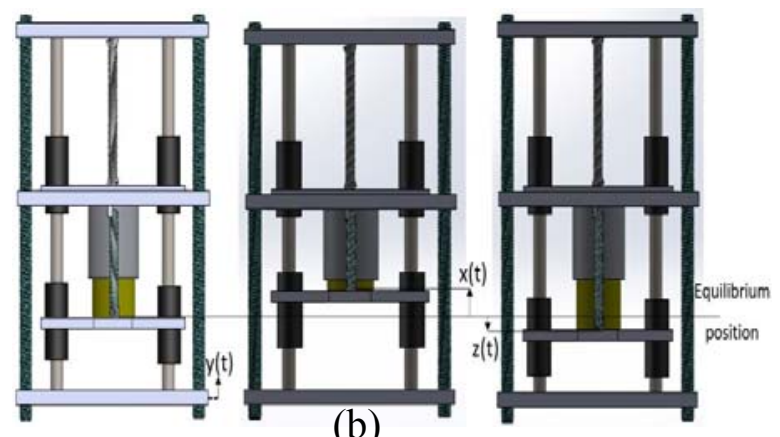

(b)

Figure 2. Illustration motion between magnet and copper coil for (a) upper stage and (b) lower stage.

The motion of upper $\mathrm{x}(\mathrm{t})$ and lower $\mathrm{z}(\mathrm{t})$ systems happen when external frequency $\mathrm{y}(\mathrm{t})$ is applied onto the system and since the electromagnetic components were attached together with mechanical subsystems, the motion of mechanical subsystems had caused the magnetic induction between magnet and coil happened which indirectly produced voltage as output. This technique can increase operating frequency range and output energy.

\section{THEORETICAL MODELING AND PARAMETERS DESIGN.}

\section{Modeling of the mechanical design.}

Mathematical modelling was developed were involving relationship between parametric factor on vibration transmissibility effect.

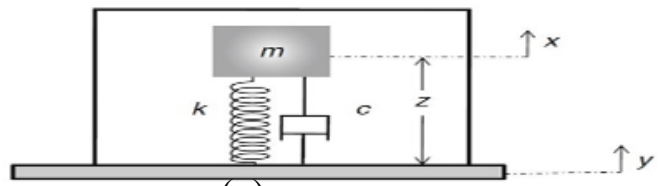

(a)

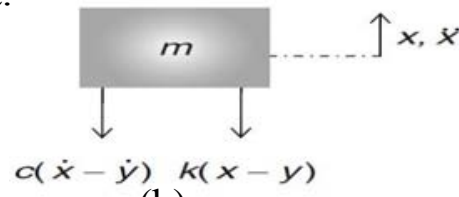

(b)

Figure 3: Schematic for SDOF of spring-mass-damper;(a) system was connected to external sources; (b) free-body diagram at an arbitrary instant including effect of support displacement, y $(\mathrm{t})$.

Based in Figure 3, $\mathrm{m}$ is seismic mass $(\mathrm{kg}), \mathrm{k}$ is spring stiffness $(\mathrm{N} / \mathrm{m})$, c is damping coefficient $(\mathrm{N} . \mathrm{s} / \mathrm{m}), \mathrm{y}$ is displacement of external force, $\mathrm{x}$ is absolute displacement of seismic mass and $\mathrm{z}$ is relative deflection of the system. According to Newton's second law, the standard form of differential equation of mass relative deflection motion can be written as

$z+2 \xi \omega_{n} z+\omega_{n}^{2} z=\omega^{2} A \sin \omega t$

Where $\omega$ is forcing frequency $(\mathrm{rad} / \mathrm{s}), \xi$ is damping ratio and $\omega_{n}$ is angular frequency of the system. Since the oscillation of the response is at the same frequency as the excitation, hence the steady state relative response can be expressed as

$z(t)=A_{1} \sin \omega t+A_{2} \cos \omega t$

Differential Eq.2 into $\frac{z}{z}(t)$ and $\vec{z}(t)$, then substituted into Eq. 1 and then simplified the solution into two equations where $r=\frac{\omega}{\omega_{n}}, z=\sqrt{A_{1}+A_{2}}$ and the end of equation become 


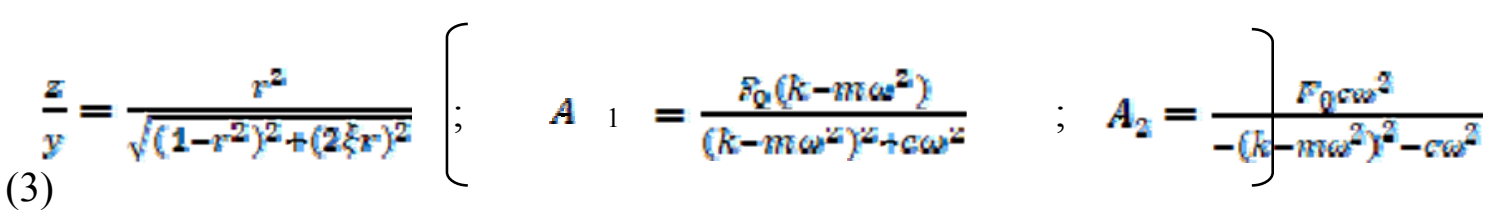

The crucial of monitoring the relative deflection $\mathrm{z}$ of the system with respect to the base $\mathrm{y}$ is to control the reflective deflection of the system during operating. The application of vibration transmissibility in electromagnetic vibration energy harvester system was introduced by William and Yates [9].From the Eq.3, the effectiveness of vibration transmissibility for energy harvester system can be controlled with three type of parameters which are damping coefficient (c), seismic mass (m) and material stiffness(k).

\section{Numerical simulation.}

In figure 4 shows the numerical simulation result (MATLAB) for vibration displacement transmissibility based on the Eq. 3 .

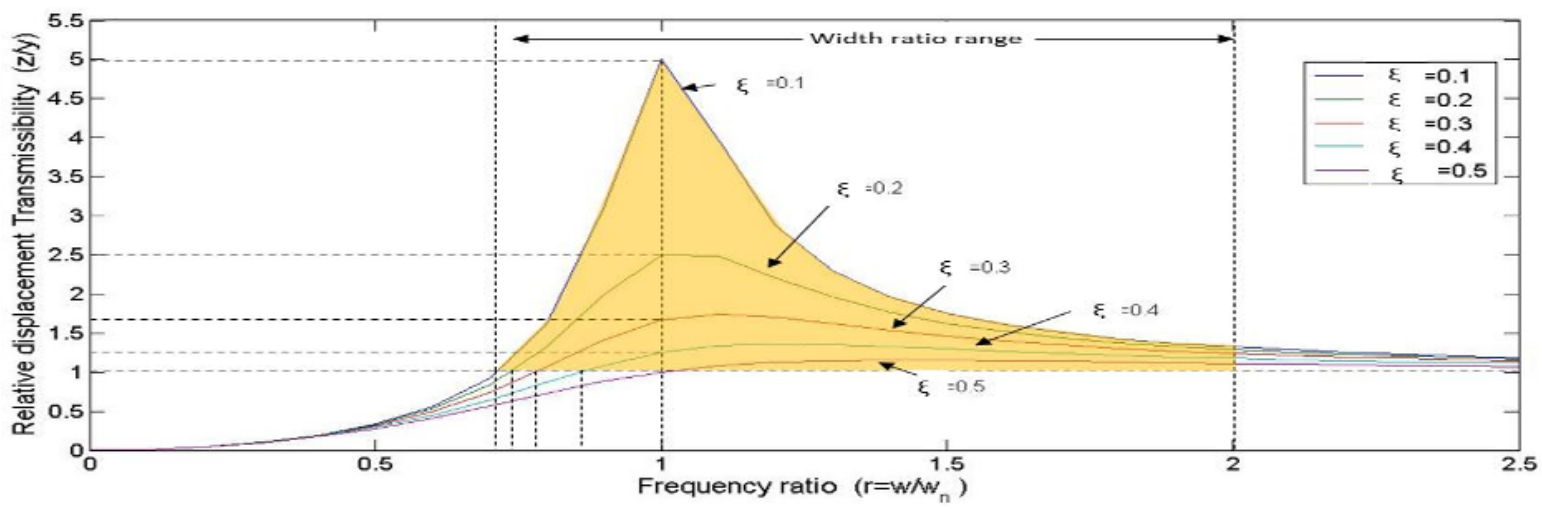

Figure 4. Relative displacement transmissibility with damping ratio $(\xi)$ below 0.5 .

Based on the graph in figure 4, smaller $\xi$ value has increased width frequency ratio range and displacement transmissibility (z/y). It will give advantage for system to operate at any frequency ratio range without depend only on resonance condition $(r=1)$. Thus, width range frequency ratio will help system to increase the performance of displacement transmissibility $(\mathrm{z} / \mathrm{y})$ even at varying external frequency value $(\omega)$. The frequency ratio $(\mathrm{r}=\omega / \omega n)$ below than value 1 and displacement transmissibility $(\mathrm{z} / \mathrm{y})$ less than value 1 are not suitable for system to operate in this region since it will limit the vibration transfer to system and indirectly it will give effect on system performance.

\section{Prototype fabrication.}

In order to proof the proposed idea, a harvester prototype was fabricated and tested. Figure 5 shows the image of fabricated prototype and the geometric parameter of components have been listed in Table 2.

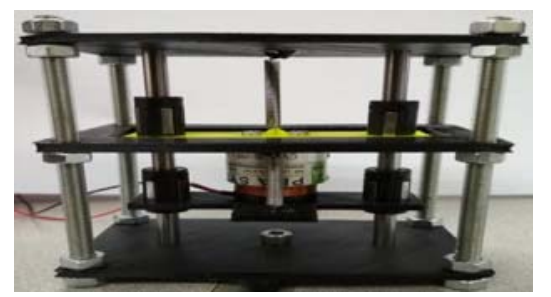

Figure 5. Prototype of energy harvester system

Table 2. Geometric parameter of components.

\begin{tabular}{|l|l|l|l|}
\hline Parameter & Value & Parameter & Value \\
\hline $\begin{array}{l}\text { Lower system } \\
\text { mass }\end{array}$ & $35.5 \mathrm{~g}$ & Upper system mass & $67 \mathrm{~g}$ \\
\hline $\begin{array}{l}\text { Overall system } \\
\text { mass }\end{array}$ & $150 \mathrm{~g}$ & Spring stiffness & $48 \mathrm{~N} / \mathrm{m}$ \\
\hline
\end{tabular}




\section{EXPERIMENTAL RESULTS AND DISCUSSION}

\section{Measurement setup}

The fabricated prototype was tested using both a vibration exciter test. The vibration exciter test was carried out by mounting the prototype on vibration exciter as shown in Figure 6. Picoscope was used to measure output voltage from prototype.

LMS DAQ (Scadas Mobile)

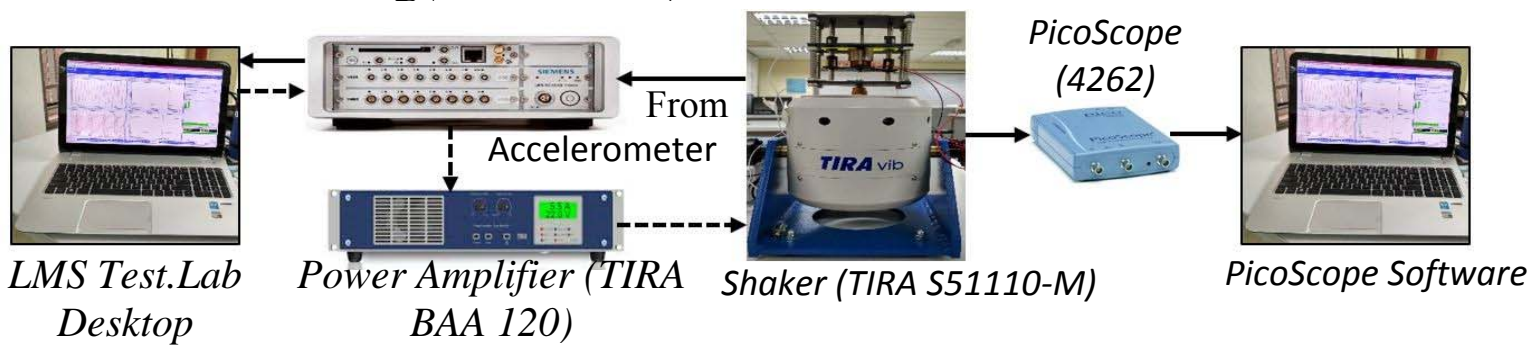

Figure 6. Schematic diagram of the vibration exciter test setup for the fabricated harvester prototype.

Experimental results and discussion.

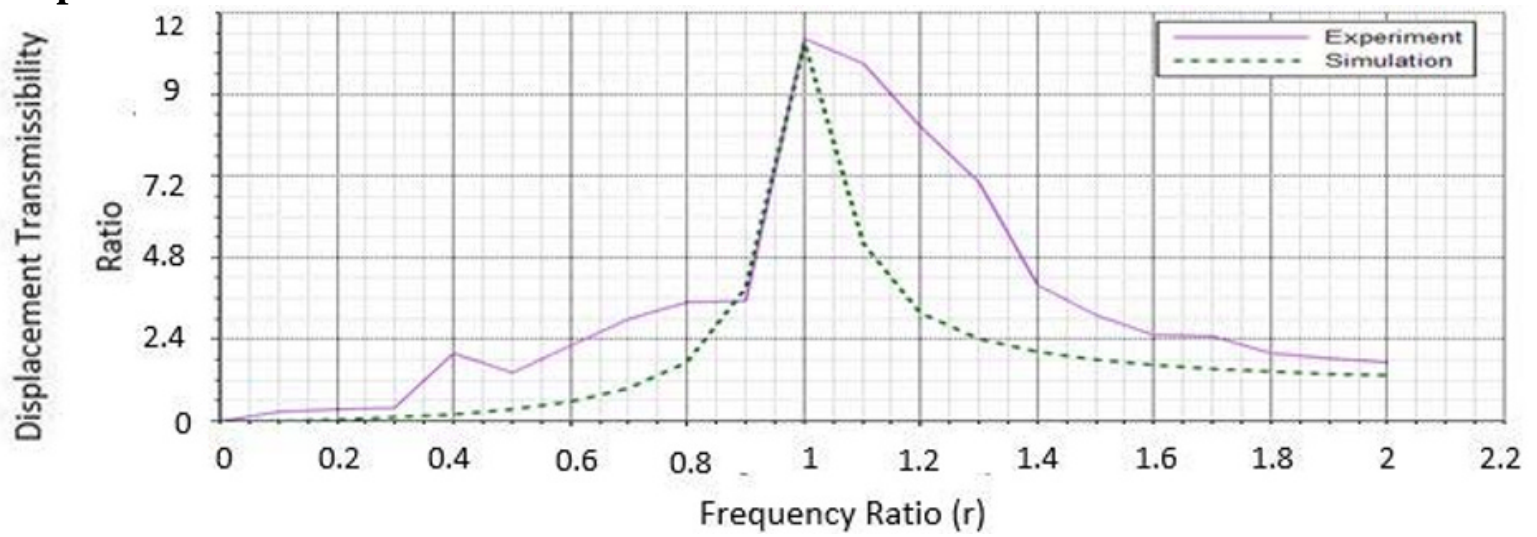

(a)

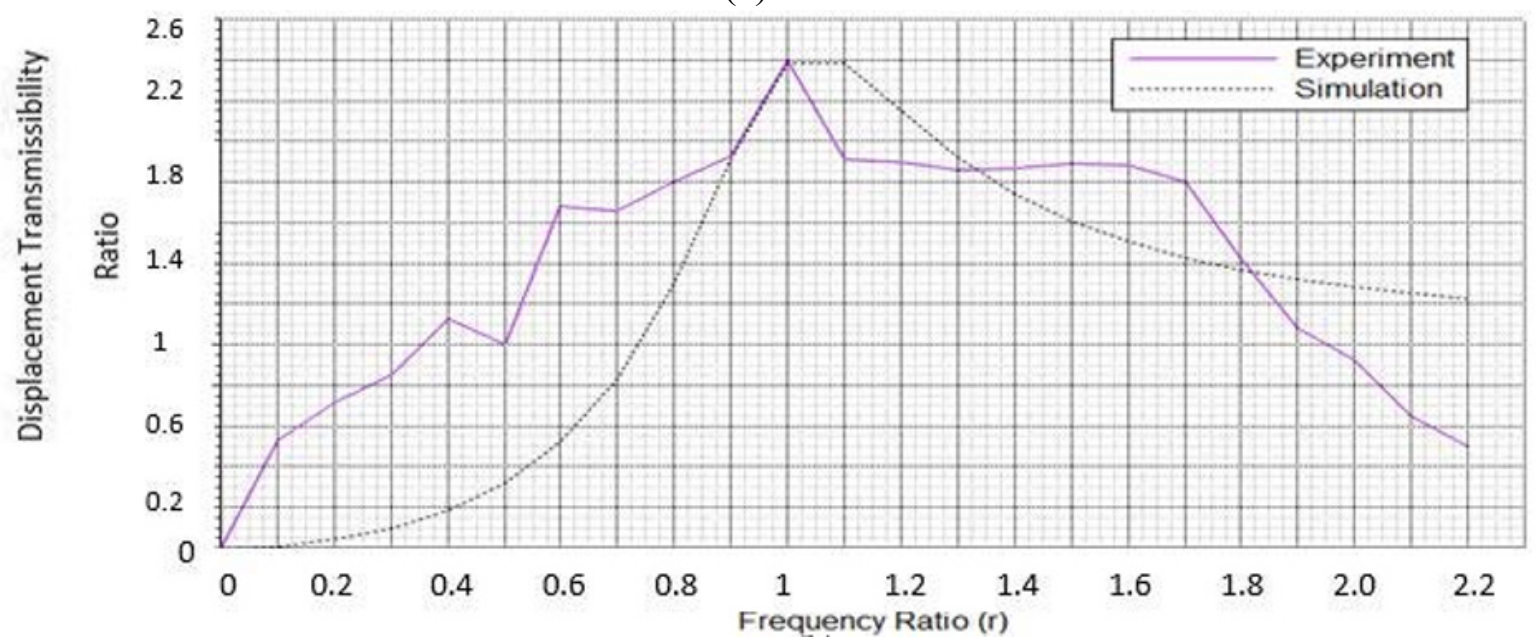

(b)

Figure 7. Comparison vibration transmissibility between experimental and simulation result for (a) upper and (b) lower system. 
Based on the graph pattern in Figure 7, the experimental result for both systems have shown the almost same pattern flow with simulation result. Frequency ratio from 0 until 0.9 shows a little bit difference gap between experimental and simulation result where the experiment results have shown the higher responded for displacement transmissibility value compared with simulation result. The reason why this happened because the factors of low damping ratio and seismic mass. From the test results for upper and lower system have proved that with two moving mechanical systems can be improved functionality of the energy harvester by increase the bandwidth frequency range during operating especially using electromagnetic as transducer because almost all the electromagnetic transducer has two components, so moving both components can enhance the overall system function compared depending only one moving electromagnetic component during operating

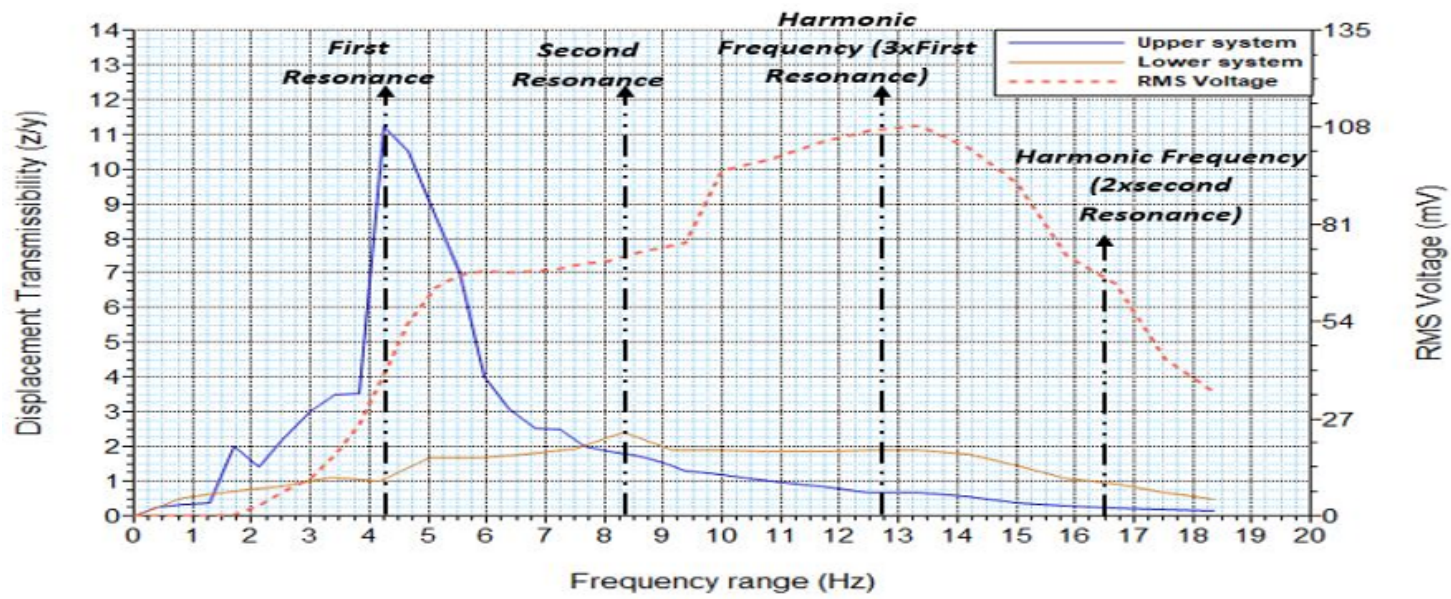

Figure 8. Output voltage result from the motion of upper and lower system at varying frequency with $0.04 \mathrm{~g}$ external amplitude value

Based in Figure 8, the effectiveness range of the operating frequency for energy harvester system was starting from $1.9 \mathrm{~Hz}$ until $18.5 \mathrm{~Hz}$. At upper natural frequency $4.26 \mathrm{~Hz}$, this system has capability to produce almost $54 \mathrm{mV}$ even at low frequency. At this condition, the upper system has shown more displacement transmissibility about 11 time bigger compare to lower, so the magnetic core had moved more across the copper coil. For the second resonance frequency at $8.34 \mathrm{~Hz}$, the harvester system has produced output voltage about $80.52 \mathrm{mV}$ which $50 \%$ more than first resonance frequency $4.26 \mathrm{~Hz}$.

\section{Conclusion.}

The research work has successfully developed an electromagnetic vibration energy harvesting system to operate at wide bandwidth frequency and low frequency. By introduced new technique which using two moving mechanical systems and two resonance frequency systems has successfully increased the output voltage of the harvester system. With controlling damping parameter value in mechanical system of energy harvester system, it has successfully made the system has capability to fully utilize the vibration level from external sources. The new mechanical mechanism concept that was applied in proposed energy harvester system has increased the effectiveness and efficiency of the vibration energy harvester system performance. 


\section{REFERENCES}

[1] J. Twiefel and H. Westermann, "Survey on broadband techniques for vibration energy harvesting,” J. Intell. Mater. Syst. Struct., pp. 1291-1302.

[2] S. P. Beeby, M. J. Tudor, and N. M. White, "Energy harvesting vibration sources for microsystems applications," Meas. Sci. Technol., vol. 17, no. 12, 2006.

[3] S. Cheng, C. Cepnik, and David P.Arnold, "Electrodynamic Vibrational Enegy Harvesting," in Micro Energy Harvesting, Weinheim, Germany: Wiley-VCH Verlag Gmbh \& Co. kGaA, 2015, pp. 175-199.

[4] D. Spreemann and Y. Manoli, "Basic Analytical Tools for the Design of Resonant Vibration Transducers," in Electromagnetic Vibration Energy Harvesting Devices, 2012.

[5] R. L. Harne and K. W. Wang, "A review of the recent research on vibration energy harvesting via bistable systems," Smart Mater. Struct., vol. 22, no. 2 , 2013.

[6] A. R. M. Siddique, S. Mahmud, and B. Van Heyst, "Energy conversion by Tshaped cantilever type electromagnetic vibration based micro power generator from low frequency vibration sources," Energy Convers. Manag., vol. 133, pp. 399-410, 2017.

[7] B. Lee and G. Chung, "Frequency tuning design for vibration-driven electromagnetic energy harvester,” pp. 801-808, 2015.

[8] B. Yang et al., "Electromagnetic energy harvesting from vibrations of multiple frequencies," vol. 19, 2009.

[9] C. B. Williams and R. B. Yates, "Analysis of a micro-electric generator for microsystems," Science (80-. )., vol. 52, pp. 8-11, 1996. 